\title{
Abrasive Wear Behaviour of Surface Modified Jute Fiber Reinforced Epoxy Composites
}

\author{
Priyadarshi Tapas Ranjan Swain ${ }^{*}$, Sandhyarani Biswas \\ ${ }^{a}$ Department of Mechanical Engineering, National Institute of Technology Rourkela, Odisha, India
}

Received: July 16, 2016; Revised: January 08, 2017; Accepted: March 09, 2017

The present article depicts the specific wear rate of jute fiber reinforced epoxy composites with different weight percentage of fiber loading $(10,20,30,40 \mathrm{wt} . \%)$ and different chemical treatments (Alkaline and Benzoyl chloride treatment). The three-body abrasive wear analysis was studied according to ASTM-G65 using a rubber wheel abrasion apparatus (dry sand wear tester) at room temperature by varying different factors like fiber content, abrasive particle size, normal load and sliding distance. To calculate the abrasive wear behaviour of jute/epoxy composites, the design of experiments approach based on Taguchi's orthogonal array has been adopted. Steady state result shows that with the inclusion of chemical treatment in jute fiber improved wear resistance capacity of the composites. Finally, scanning electron microscope (SEM) studies revealed the morphologies worn surface of the composites such as micro-ploughing, formation of debris, micro cracking and fiber matrix de-bonding.

Keywords: Three-body abrasive wear, jute fiber, Taguchi experimental design, steady state, surface treatments

\section{Introduction}

More than two decades, fiber-reinforced polymer composites have acknowledged tribo-engineering materials, which are consistently used in mechanical components such as bearings, bushes, bearing cages, gears, cams, gears, brakes, clutches, seals bearings, transmission belts, tank track pads, rollers, office automation machinery and artificial joints etc. where wear performance in non-lubricated condition is a basic parameter for the material selection. ${ }^{1-6}$ With consumer demand, new materials have enforced to replace conventional non-renewable materials in manufacturing industries such as automotive, construction, and packaging. ${ }^{7}$ These days increasing the interest of natural fiber polymer composites are being chosen over the synthetic based fiber composites due to the several advantages such as easy availability, low density, low cost, biodegradability, a range of mechanical properties and less abrasiveness. ${ }^{8-12}$ From various natural fibers, jute appears to be a promising fiber because of its high aspect ratio and toughness in comparison to other natural fibers. Generally, natural fibers are not problem free alternatives and their structural compositions like cellulose, hemicelluloses, lignin, pectin and waxy elements which allow moisture absorption from the environment which leads to poor bonding with the matrix materials. ${ }^{13}$ The alternative way to find out to alter of natural fiber with pre-treatments and their effects on the interfacial adhesive mechanism of natural fiber and polymer composites. ${ }^{14}$

In recent past, much research has been studied on tribological behaviour of polymer composites. ${ }^{15-23}$ The main focus of the attention is the methods for reducing wear as

* e-mail: swainptr@gmail.com the cost of replacing worn parts which is a major expense in many processes. Abrasive wear is recognized as the most important wear among all form of wears which contributes about $63 \%$ of all cost in the industries associated with power, automobile, pumps handling industrial fluids and earth moving equipment. ${ }^{24} \mathrm{Abrasive}$ wear may be defined as where hard asperities on one surface move across a softer surface under load penetrate and removes material from the softer surface, leaving grooves. ${ }^{18}$ It can be traditionally divided into two parts, i.e. two-body and three-body abrasion. In two-body abrasion, abrasive wear caused when a rough surface or fixed abrasive particle slides over a surface and removes material; three body abrasions occurs, when the material of the surface is removed by the sliding and rolling action of the loose particles. Mainly, three-body abrasive wear is more prevailing than two-body abrasive wear, ${ }^{15,16}$ especially in engineering, industrial area of agriculture, mineral processing, mining and earth moving instrument. ${ }^{17}$ The rate of abrasion depends on the surface characteristics, the flow rate of abrasives, nature of abrasives and other environmental factors. The abrasive wear is controlled by many factors such as operating conditions, design parameters, the abrasion characteristics and material properties. The wear data of the composites reveal that the wear behavior strongly depends on the operating parameters. For abrasion of polymeric composites, there have been many attempts to understand the tribo-behavior of various materials in various operating parameters and efforts. Exhaustive literature review on three body abrasion behavior of polymer composites that parameters namely fiber loading, sliding distance, normal load and abrasive size etc. effects the wear behaviour of polymer composites. ${ }^{25-28}$ 
In past years a number of studies on polymers and their composites subjected to abrasive wear have been reported. ${ }^{29-35}$ It has been revealed that with the inclusion of chemical treatment into the fiber, the wear resistance property increased. ${ }^{36-39}$ The linkages formation at the interface of matrix and fibers during deformation played a major role in the wear process. The chemical treatment of the fiber to improve the adhesion between the fiber surface and the polymer matrix is aligned by modifying the fiber surface and the fiber strength. Among the various techniques of pre-treatment, treatment with alkalis (mercerizing) and benzoylation, treatment are the best methods for surface modification of natural fibers described by kalia et al. ${ }^{40}$ revised in a manuscript.

The thorough literature survey cited above reveals that there is ample scope to understand and establish the abrasive wear mechanism of fiber loaded epoxy composites. Although a great deal of work has already been done on abrasive wear behavior of composites, however, the study of chemical treated three-body abrasive wear behavior of thermoset composites is limited. An attempt has been made in the present work to study the three-body abrasive wear behaviour of untreated and chemically treated jute fiber reinforced epoxy based composites. The Taguchi experimental design study was carried out for the parametric analysis of abrasive wear process. Steady state study was also done to understand the effect of sliding distance and normal load on the abrasive wear performance.

\section{Materials and Fabrication}

\subsection{Materials and composite preparation}

Jute is extracted from plants in the genus Corchorus, family Tiliaceae. Cross-plied woven jute fiber mats are used to reinforce in Epoxy LY 556 is taken as matrix material in the present study. The jute fiber is collected from local sources. It is extracted from bast or skin of the plant likewise as that of kenaf, industrial hemp, flax (linen), ramie etc. The epoxy resin (Bisphenol-A Diglycidyl-Ether, chemically belonging to the 'epoxide' family) added with room temperature curing hardener (HY 951) with a ratio of $10: 1$ by weight as prescribed by the manufacturer. It has been used widely because of its superior strength, excellent adhesion, good chemical resistance and excellent performance at elevated temperatures. The light compression moulding method of composite laminates are carried out by conventional hand layup technique under a load of about $25 \mathrm{~kg}$ for $24 \mathrm{~h}$ before it detached from the pattern. The composites were made-up to a dimension of $200 \times 200$ $\mathrm{mm}^{2}$ sheet. As per the ASTM standards, the abrasion test specimens of suitable dimension $\left(75 \times 25 \times 3 \mathrm{~mm}^{3}\right)$ were obtained by cutting composites sheets using a diamond cutter. The detail designation and composition of composites are given in Table 1.

\subsubsection{Chemical treatment of jute fiber}

To increase the bonding between fiber and polymer matrix, chemical treatment was employed. Chemical treatment reduces the moisture absorption and hydrophilic nature of the fiber which progresses the hydrophobicity behaviour of the fiber along with the strength of the material. Therefore, modified composite obtain better performance as compared to unmodified fiber composite materials. Two different types of surface treatment method have been used for the present study such as alkali treatment and benzoyl chloride (benzoylation) treatment.

\subsubsection{Alkali treatment}

Jute fibers were soaked in a $1 \% \mathrm{NaOH}$ solution at $30^{\circ} \mathrm{C}$, maintaining a liquor ratio of 15:1. The fibers were kept immersed in the alkali solution for $4 \mathrm{~h}$. The fibers were then washed several times with fresh water to remove any $\mathrm{NaOH}$ sticking to the fiber surface, defused with dilute acetic acid, and lastly washed again with distilled water. The fibers were then dried at room temperature for $24 \mathrm{~h}$, followed by oven drying at $80^{\circ} \mathrm{C}$ for $6 \mathrm{~h}$.

\subsubsection{Benzoylation treatment}

Firstly, the pre-treated jute fibers were suspended in $\mathrm{NaOH}$ solution to activate the hydroxyl groups of the cellulose and lignin and then agitated with benzoyl chloride for $15 \mathrm{~min}$. The mixture was filtered and washed thoroughly with distilled water and dried. The isolated fibers were then soaked in ethanol for $1 \mathrm{~h}$ to remove the benzoyl chloride and finally were washed with fresh water several times and dried in an oven maintained at $80^{\circ} \mathrm{C}$ for $6 \mathrm{~h}$.

\subsection{Abrasive wear test method}

The three-body abrasive wear tests were performed as per ASTM-G65 ${ }^{41}$ standards using a dry sand/rubber wheel abrasion tester as shown schematically in Figure 1. Before conducting the test, the surface of the composites specimen were cleaned with a soft paper soaked in acetone cleaner and its initial weight determined in a high precision digital electronic balance (1mg accuracy, CONTECH) before it was mounted in the sample holder. The device carries abrasive hopper, nozzle, rubber wheel, steel disk, sample holder, particle collecting bag, and an arrangement for load application. The diameter of the rubber wheel used is $228 \mathrm{~mm}$ and the tests were conducted at a rotational speed of $200 \pm 5$ $\mathrm{rpm}$. The abrasive particles were directed to flow between the contacting surface of the sample test specimen and rotating abrasive wheel composed of steel disc with chlorobutyl rubber tyre (hardness: $60 \pm 5$ shore) via a nozzle. The specimen was pressed against the rotating abrasive wheel at a specified 
Table 1. Designation and detailed composition of the composites

\begin{tabular}{|c|c|c|c|}
\hline $\begin{array}{l}\text { Untreated } \\
\text { Composites }\end{array}$ & $\begin{array}{l}\text { Alkali treated } \\
\text { Composites }\end{array}$ & $\begin{array}{l}\text { Benzoylated } \\
\text { Composites }\end{array}$ & Compositions \\
\hline $\mathrm{C} 1$ & CA1 & CB1 & Fiber loading $(10 \%)+$ Epoxy $(90 \%)$ \\
\hline $\mathrm{C} 2$ & $\mathrm{CA} 2$ & $\mathrm{CB} 2$ & Fiber loading $(20 \%)+$ Epoxy $(80 \%)$ \\
\hline C3 & $\mathrm{CA} 3$ & CB3 & Fiber loading $(30 \%)+$ Epoxy $(70 \%)$ \\
\hline $\mathrm{C} 4$ & CA4 & CB4 & Fiber loading $(40 \%)+$ Epoxy $(60 \%)$ \\
\hline
\end{tabular}

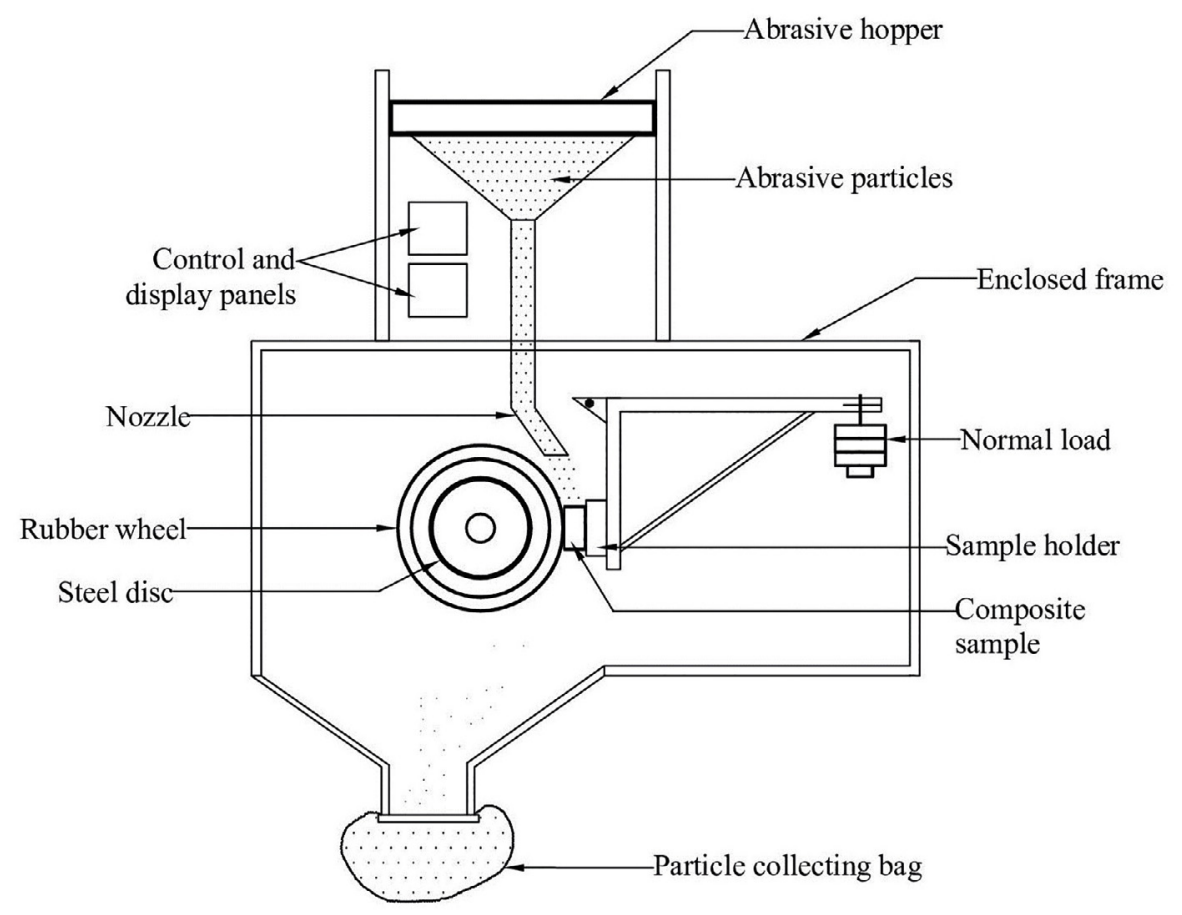

Figure 1. Schematic diagram of abrasive wear test rig.

force by means of a lever arm while a controlled flow of the abrasive particles abraded the test surface. The rotation of the wheel was such that its contacting face moves in the direction of abrasive flow. The pivot axis of the lever arm lies within a plane, which is approximately tangent to the rubber wheel surface and normal to the horizontal diameter along which the load is applied. The steady-state analyses of the composites were performed to understand the effect of sliding distance and normal load on the specific wear rate. At the end of the experiment, the sample was detached, properly cleaned and again the final weight measured. The difference in weight calculated is a measure of abrasive wear loss. The average values of three tests were evaluated in the analysis. The specific wear rate $\left(\mathrm{W}_{\mathrm{s}}\right)$ was calculated from the equation (1).

$$
W_{s}=\frac{\Delta M}{\rho L F}\left(\mathrm{~cm}^{3} / N-m\right)
$$

Where $\Delta \mathrm{M}(\mathrm{gm})$ is the mass loss of the specimen during the test, $\rho\left(\mathrm{gm} / \mathrm{cm}^{3}\right)$ is the density of the specimen used, $\mathrm{L}$ (m) is the sliding distance, and F (N) is the load applied to the specimen.

\subsection{Taguchi experimental design}

The design of experiments based on Taguchi method is engaged for the parametric analysis, which becomes an attractive and widely accepted tool among engineers and scientists. It is a blend of statistical and mathematical techniques used in an empirical study. This technique helps to attain the best parameters for the optimal conditions with the least number of analytical studies. The most important stage in the design of experiment lies in the selection of the control factors. An exhaustive review of literature based on abrasion behavior of composites discovered that factors such as fiber loading, normal load, sliding distance, and abrasive size largely influence the abrasive wear rate. Each parameter has four different control levels under which the specimens endured for abrasive wear, as represented in Table 2.

In the present work, the effect of four parameters over the wear was studied using $\mathrm{L}_{16}$ orthogonal array which has 
Table 2. Levels of the variables used in the experiment.

\begin{tabular}{|c|c|c|c|c|c|}
\hline \multirow[b]{2}{*}{ Control factors } & \multicolumn{5}{|c|}{ Levels } \\
\hline & I & II & III & IV & Units \\
\hline Sliding distance (A) & 50 & 60 & 70 & 80 & $\mathrm{~m}$ \\
\hline Fiber loading (B) & 10 & 20 & 30 & 40 & wt. $\%$ \\
\hline Normal load (C) & 10 & 20 & 30 & 40 & $\mathrm{~N}$ \\
\hline Abrasive size (D) & 100 & 200 & 300 & 400 & $\mu \mathrm{m}$ \\
\hline
\end{tabular}

16 rows corresponding to the number of variables selected. In conventional full factorial design, it would require $4^{4}=$ 256 runs to study four factors each at four levels whereas, Taguchi's factorial design approach reduces it to only 16 runs offering a great advantage in terms of experimental time and cost. The various combinations of the experimental study are shown Table 3 for Supporting Information. The signal-to-noise $(\mathrm{S} / \mathrm{N})$ ratio characteristics can be divided into three categories, viz. "nominal is the best", "smaller the better", and "larger the better" characteristics. In this analysis, "smaller the better" characteristics was selected to analyse the wear rate because specific wear rate is shown by a smaller value, which is the better characteristic. The $\mathrm{S} / \mathrm{N}$ ratio for the smaller is the better characteristic is given by the expression in equation (2)

$$
\frac{S}{N}=-10 \log \frac{1}{n}\left(\sum y\right)^{2}
$$

Where $\mathrm{n}$ is the number of observations and $\mathrm{y}$ is the observed data.

\subsection{Surface morphology study}

Studies on the worn surfaces of the specimens were examined by scanning electron microscope (SEM) JEOL JSM-6480LV. The abraded specimens were mounted on stubs with silver paste. To enhance the conductivity of the abraded samples, a thin film of platinum was vacuum-evaporated onto them before the micrographs were captured.

\section{Results and Discussion}

\subsection{Wear analysis using experimental design}

The specific wear rates of different types of reinforced composites (untreated, alkali-treated and benzoyl chloride treated composites) found for all the 16 test runs for each set of composites along with the corresponding $\mathrm{S} / \mathrm{N}$ ratios are presented in Table 3.

This table shows the overall mean for the $\mathrm{S} / \mathrm{N}$ ratio of the wear rate is found to be 73.96, 82.30 and $84.24 \mathrm{db}$ respectively. MINITAB 16 (Minitab Statistical Software) is specifically used for design-of-experiment applications purpose. Figure 2 shows the main effect plot for $\mathrm{S} / \mathrm{N}$ ratios of individual control factors. The horizontal axis shows the control factors and vertical axis shows the $\mathrm{S} / \mathrm{N}$ ratios. The analysis of the results leads to the conclusion that control factor combination of $\mathrm{A}_{3}, \mathrm{~B}_{3}, \mathrm{C}_{2}$, and $\mathrm{D}_{1}$ gives the minimum wear rate for untreated composites, $\mathrm{A}_{2}, \mathrm{~B}_{3}, \mathrm{C}_{1}$, and $\mathrm{D}_{1}$ gives the minimum wear rate for alkali treated composited and $\mathrm{A}_{2}, \mathrm{~B}_{3}, \mathrm{C}_{1}$, and $\mathrm{D}_{2}$ gives the minimum wear rate for benzoyl chloride treated composites respectively which is shown in Figure 2.

\subsubsection{Confirmation experiment}

The confirmation test is used to verify the experimental result suggested by Taguchi. ${ }^{42}$ The optimal combination of parameters has been explored in the previous analysis. But, the final phase of any experimental design approach is to predict and verify improvements in observed values through the use of the optimal combination level of parameters. The confirmation experiment is performed by conducting an arbitrary new set of factor settings $\mathrm{A}_{1} \mathrm{~B}_{3} \mathrm{C}_{4} \mathrm{D}_{2}$ to predict the specific wear rate for untreated $A_{3} B_{4} C_{1} D_{2}$ to predict the specific wear rate for Alkali treated and $\mathrm{A}_{3} \mathrm{~B}_{1} \mathrm{C}_{2} \mathrm{D}_{4}$ to predict the specific wear rate for Benzoyl chloride treated jute epoxy composites. The estimated $\mathrm{S} / \mathrm{N}$ ratio for specific wear rate can be calculated with the help of following prediction equation:

$$
\begin{aligned}
& \eta_{W_{S}}=\eta_{A_{1}}+\eta_{B_{3}}+\eta_{C_{4}}+\eta_{D_{2}}-4 \eta_{m} \\
& \eta_{W_{S}}=\eta_{A_{3}}+\eta_{B_{4}}+\eta_{C_{1}}+\eta_{D_{2}}-4 \eta_{m} \\
& \eta_{W_{S}}=\eta_{A_{3}}+\eta_{B_{1}}+\eta_{C_{2}}+\eta_{D_{4}}-4 \eta_{m}
\end{aligned}
$$

Where, $\eta_{W S}$ is the total mean of $\mathrm{S} / \mathrm{N}$ ratio $\eta_{A l}, \eta_{B I}$, $\eta_{C l}, \eta_{D 4}$, are the mean of $\mathrm{S} / \mathrm{N}$ ratio at the optimal factor levels.

The predicted $\mathrm{S} / \mathrm{N}$ ratio values at optimal settings are $80.8857 \mathrm{~dB}$ for untreated, $91.9030 \mathrm{~dB}$ for alkali treated and $79.6354 \mathrm{~dB}$ for benzoyl chloride treated composites. For the confirmatory test, new experiments are designed and conducted with the optimum levels of the parameter using a dry sand rubber/wheel abrasion tester. Table 4 shows the results of confirmation experiment and found an error of 4.403, 3.655 and $2.990 \%$ for the $\mathrm{S} / \mathrm{N}$ ratio of untreated, alkali-treated and benzoyl chloride treated composites respectively. 
Table 3. Experimental design using $\mathrm{L}_{16}$ orthogonal array

\begin{tabular}{lcccccccccc}
\hline Expt No. & $\begin{array}{c}\text { Sliding } \\
\text { distance } \\
(\mathrm{m})\end{array}$ & $\begin{array}{c}\text { Fiber } \\
\text { loading } \\
(\mathrm{wt} . \%)\end{array}$ & $\begin{array}{c}\text { Normal } \\
\text { load }(\mathrm{N})\end{array}$ & $\begin{array}{c}\text { Abrasive } \\
\text { size }(\mu \mathrm{m})\end{array}$ & $\begin{array}{c}\text { Ws }(\mathrm{UT}) \\
\left(\frac{\mathrm{cm}^{3}}{\mathrm{~N}-\mathrm{m}}\right)\end{array}$ & $\begin{array}{c}\text { S/N ratio } \\
(\mathrm{db})\end{array}$ & $\begin{array}{c}\text { Ws (AT) } \\
\left(\frac{\mathrm{cm}^{3}}{\mathrm{~N}-\mathrm{m}}\right)\end{array}$ & $\begin{array}{c}\text { S/N ratio } \\
(\mathrm{db})\end{array}$ & $\begin{array}{c}\text { Ws }(\mathrm{BT}) \\
\left(\frac{\mathrm{cm}^{3}}{\mathrm{~N}-\mathrm{m}}\right)\end{array}$ & $\begin{array}{c}\text { S/N ratio } \\
(\mathrm{db})\end{array}$ \\
\hline 1 & 50 & 10 & 10 & 100 & $1.39 \mathrm{E}-04$ & 77.12 & $5.55 \mathrm{E}-05$ & 85.11 & $4.00 \mathrm{E}-05$ & 87.97 \\
2 & 50 & 20 & 20 & 200 & $1.10 \mathrm{E}-04$ & 79.19 & $6.20 \mathrm{E}-05$ & 84.15 & $5.67 \mathrm{E}-05$ & 84.92 \\
3 & 50 & 30 & 30 & 300 & $1.07 \mathrm{E}-04$ & 79.41 & $6.67 \mathrm{E}-05$ & 83.52 & $8.25 \mathrm{E}-05$ & 81.67 \\
4 & 50 & 40 & 40 & 400 & $4.06 \mathrm{E}-04$ & 67.83 & $1.75 \mathrm{E}-04$ & 75.16 & $1.51 \mathrm{E}-04$ & 76.45 \\
5 & 60 & 10 & 20 & 300 & $2.15 \mathrm{E}-04$ & 73.34 & $1.22 \mathrm{E}-04$ & 78.24 & $8.36 \mathrm{E}-05$ & 81.55 \\
6 & 60 & 20 & 10 & 400 & $7.68 \mathrm{E}-04$ & 62.30 & $3.51 \mathrm{E}-05$ & 89.09 & $2.15 \mathrm{E}-05$ & 93.34 \\
7 & 60 & 30 & 40 & 100 & $1.12 \mathrm{E}-04$ & 78.98 & $6.65 \mathrm{E}-05$ & 83.54 & $6.52 \mathrm{E}-05$ & 83.72 \\
8 & 60 & 40 & 30 & 200 & $2.55 \mathrm{E}-04$ & 71.88 & $5.39 \mathrm{E}-05$ & 85.37 & $5.06 \mathrm{E}-05$ & 85.91 \\
9 & 70 & 10 & 30 & 400 & $3.45 \mathrm{E}-04$ & 69.25 & $2.72 \mathrm{E}-04$ & 71.31 & $1.68 \mathrm{E}-04$ & 75.48 \\
10 & 70 & 20 & 40 & 300 & $2.60 \mathrm{E}-04$ & 71.71 & $2.06 \mathrm{E}-04$ & 73.71 & $1.40 \mathrm{E}-04$ & 77.08 \\
11 & 70 & 30 & 10 & 200 & $6.19 \mathrm{E}-05$ & 84.16 & $1.89 \mathrm{E}-05$ & 94.45 & $1.77 \mathrm{E}-05$ & 95.03 \\
12 & 70 & 40 & 20 & 100 & $8.42 \mathrm{E}-05$ & 81.50 & $3.06 \mathrm{E}-05$ & 90.28 & $2.83 \mathrm{E}-05$ & 90.98 \\
13 & 80 & 10 & 40 & 200 & $3.50 \mathrm{E}-04$ & 69.11 & $3.12 \mathrm{E}-04$ & 70.11 & $1.93 \mathrm{E}-04$ & 74.27 \\
14 & 80 & 20 & 30 & 100 & $1.36 \mathrm{E}-04$ & 77.36 & $7.24 \mathrm{E}-05$ & 82.80 & $6.52 \mathrm{E}-05$ & 83.72 \\
15 & 80 & 30 & 20 & 400 & $2.24 \mathrm{E}-04$ & 72.99 & $6.31 \mathrm{E}-05$ & 84.00 & $5.99 \mathrm{E}-05$ & 84.46 \\
16 & 80 & 40 & 10 & 300 & $4.35 \mathrm{E}-04$ & 67.24 & $5.03 \mathrm{E}-05$ & 85.96 & $2.70 \mathrm{E}-05$ & 91.38 \\
\hline
\end{tabular}
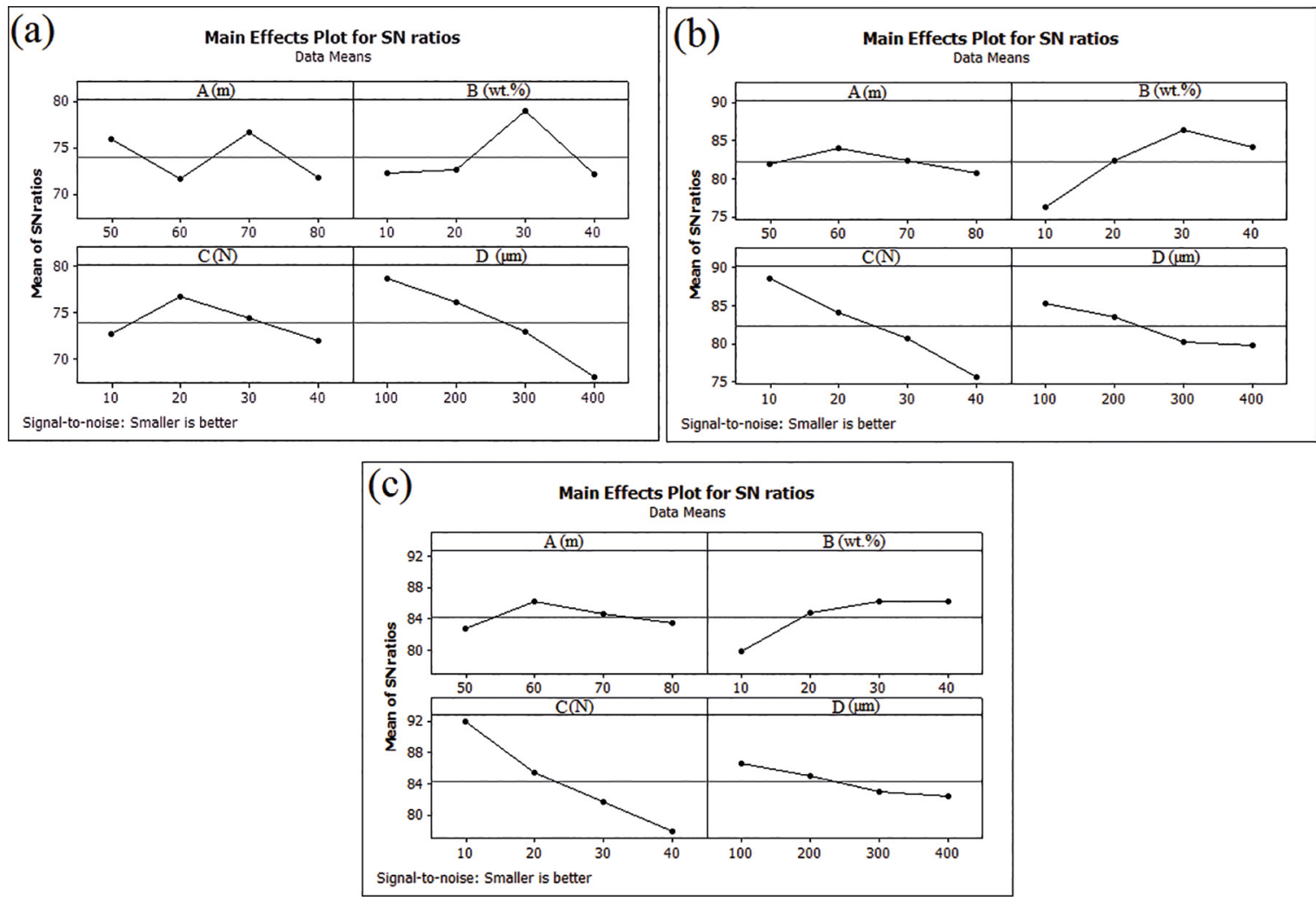

Figure 2. Effect of control factors on specific wear rate for (a) Untreated (b) Alkali treated (c) Benzoyl chloride treated jute fiber-epoxy composites.

\subsection{ANOVA and the effects of factors}

Analysis of variance (ANOVA) is performed based on Taguchi experimental results to find out the statistical significance of various control factors like sliding distance, fiber loading, normal load and abrasive size on the specific wear rate of the composites. Experimental analysis of 
Table 4. Results of confirmation experiment

\begin{tabular}{lccc}
\hline Specific Wear Rate & \multicolumn{2}{c}{ Optimal Condition } & Error (\%) \\
\hline Specific Wear Rate (UT) Level & Predicted & $\mathrm{A}_{1} \mathrm{~B}_{3} \mathrm{C}_{4} \mathrm{D}_{2}$ & Experiment \\
S/N ratio (dB) & 80.8857 & $\mathrm{~A}_{1} \mathrm{~B}_{3} \mathrm{C}_{4} \mathrm{D}_{2}$ & 77.3241 \\
Specific Wear Rate (AT) Level & $\mathrm{A}_{3} \mathrm{~B}_{4} \mathrm{C}_{1} \mathrm{D}_{2}$ & 77.403 \\
S/N ratio (dB) & 91.9030 & $\mathrm{~A}_{3} \mathrm{~B}_{4} \mathrm{C}_{1} \mathrm{D}_{2}$ & \\
Specific Wear Rate (BT) Level & $\mathrm{A}_{3} \mathrm{~B}_{1} \mathrm{C}_{2} \mathrm{D}_{4}$ & 88.5436 & 3.655 \\
S/N ratio (dB) & 79.6354 & $\mathrm{~A}_{3} \mathrm{~B}_{1} \mathrm{C}_{2} \mathrm{D}_{4}$ & \\
\hline
\end{tabular}

ANOVA is done by using MINITAB 16 software. This analysis is undertaken for a level of significance of $5 \%$. The last column of the table indicates that the main effects are highly significant (all have very small p-values).

Table 5 indicates the result of ANOVA with the specific wear rate of untreated jute fiber epoxy based composites taken in this study. It can be observed that abrasive Size ( $p=$ $0.025)$ and fiber loading $(p=0.061)$ have great influence on specific wear rate. However, sliding distance $(p=0.102)$ and normal load $(\mathrm{p}=0.171)$ show the less significant contribution to specific wear rate of the composites.

Table 6 and 7 represents the result of ANOVA with the specific wear rate of alkali treated and benzoyl chloride treated of jute epoxy based composites taken in this investigation. In Table 6 , It can be observed that normal load $(p=0.006)$, fiber loading $(p=0.012)$ and abrasive Size $(p=0.049)$ have great influence on specific wear rate. The remaining factor sliding distance $(p=0.229)$ shows less significant contribution to the specific wear rate of the composites.

It can be observed from Table 7 that normal load $(p=0.001)$, fiber loading $(p=0.010)$ and abrasive Size $(\mathrm{p}=0.037)$ have great influence on specific wear rate. However, sliding distance $(p=0.229)$ is the less significant effect on the specific wear rate of the composites.

Table 5. ANOVA for specific wear rate of untreated jute fiber-epoxy composites

\begin{tabular}{lcccccc}
\hline Source & DF & Seq SS & Adj SS & Adj MS & F & P \\
\hline Sliding Distance & 3 & 86.63 & 86.63 & 28.877 & 5.30 & 0.102 \\
Fiber Loading & 3 & 129.99 & 129.99 & 43.331 & 7.96 & 0.061 \\
Normal Load & 3 & 55.44 & 55.44 & 18.479 & 3.39 & 0.171 \\
Abrasive Size & 3 & 251.38 & 251.38 & 83.794 & 15.39 & 0.025 \\
Residual Error & 3 & 16.33 & 16.33 & 5.444 & & \\
Total & 15 & 539.77 & & & & \\
\hline
\end{tabular}

Table 6. ANOVA for specific wear rate of alkali treated jute fiber-epoxy composites

\begin{tabular}{lcccccc}
\hline Source & DF & Seq SS & Adj SS & Adj MS & F & P \\
\hline Sliding Distance & 3 & 22.852 & 22.852 & 7.617 & 2.57 & 0.229 \\
Fiber Loading & 3 & 230.136 & 230.136 & 76.712 & 25.90 & 0.012 \\
Normal Load & 3 & 362.864 & 362.846 & 120.949 & 40.83 & 0.006 \\
Abrasive Size & 3 & 83.555 & 83.555 & 27.852 & 9.40 & 0.049 \\
Residual Error & 3 & 8.886 & 8.886 & 2.962 & & \\
Total & 15 & 708.275 & & & & \\
\hline
\end{tabular}

Table 7. ANOVA for specific wear rate of benzoyl chloride treated jute fiber-epoxy composites

\begin{tabular}{lcccccc}
\hline Source & DF & Seq SS & Adj SS & Adj MS & F & P \\
\hline Sliding Distance & 3 & 26.258 & 26.258 & 8.753 & 6.82 & 0.075 \\
Fiber Loading & 3 & 109.957 & 109.957 & 36.652 & 28.55 & 0.010 \\
Normal Load & 3 & 430.319 & 430.319 & 143.440 & 111.73 & 0.001 \\
Abrasive Size & 3 & 44.795 & 44.795 & 14.932 & 11.63 & 0.037 \\
Residual Error & 3 & 3.851 & 3.851 & 1.284 & & \\
Total & 15 & 615.179 & & & & \\
\hline
\end{tabular}




\subsection{Effect of normal load and sliding distance on specific wear rate of the composites}

Figure 3 (a), (b) and (c) represents the effect of specific wear rate on a normal load of untreated, alkali-treated and benzoyl chloride treated jute fiber-reinforced epoxy composites respectively. In order to study the effect of normal load of abrasives at a constant sliding distance $(50 \mathrm{~m})$ and abrasive size $(300 \mathrm{~mm})$, the steady-state specific wear rate of the composites are calculated by varying the normal load from 10 to $40 \mathrm{~N}$. The result shows the irregular trend of specific wear rate jute fiber-reinforced composites. Similar type of observation is also described by the past investigators. ${ }^{43}$ The higher wear rate of the composites occurs which imply that there are fewer fibers to support the matrix and because of this abrasive particles form large depth grooves and separate cutting method of the abrasive wear may be a governing wear mechanism. The possible wear mechanism for minimum specific wear rate in the composite specimens may be ploughing or wedge formation. ${ }^{44}$ The resistance to wear is improved by adding the fiber on the epoxy resin and hence less specific wear rates are obtained. Chand et al. ${ }^{45}$ also observe that the abrasive wear resistance of the composites improved with the addition of fibers due to the cellular structure of natural fibers. Epoxy resin exhibits brittle fracture while the fiber shows flexible and therefore reduce the disintegration of matrix i.e. reduces the brittle fracture of the epoxy matrix and offers higher shearing resistance. Fiber existence does not allow easy removal of debris and requires higher energy for detachment from the matrix. These fibers improve the stiffness and strength of the resin, while the matrix transmits the load to the stiffer fibers for which increase of interfacial bond strength increases the resistance of composites against any damage.

The effect of specific wear rate on a sliding distance of untreated, alkali-treated and benzoyl chloride treated jute fiber-reinforced epoxy composites are shown in Figure 4 (a), (b) and (c) respectively. In this case, steady-state specific wear rate of the composites are calculated by varying the sliding distance from 50 to $80 \mathrm{~m}$ with constant normal load $(20 \mathrm{~N})$ and abrasive size $(300 \mathrm{~mm})$. From the Figure 4, it has been concluded that the specific wear rate of composites decreases with increase in sliding distance. This is because at a low sliding distance, abrasive particles initially are in contact with low modulus matrix (low hardness) on the surface of the composite and at higher sliding distances lesser wear rate was witnessed due to the resistance offered by jute fibers. These exposed jute fibers, because of their high hardness values, provide improved resistance against the abrasion and this implies, abrasive particles have to work
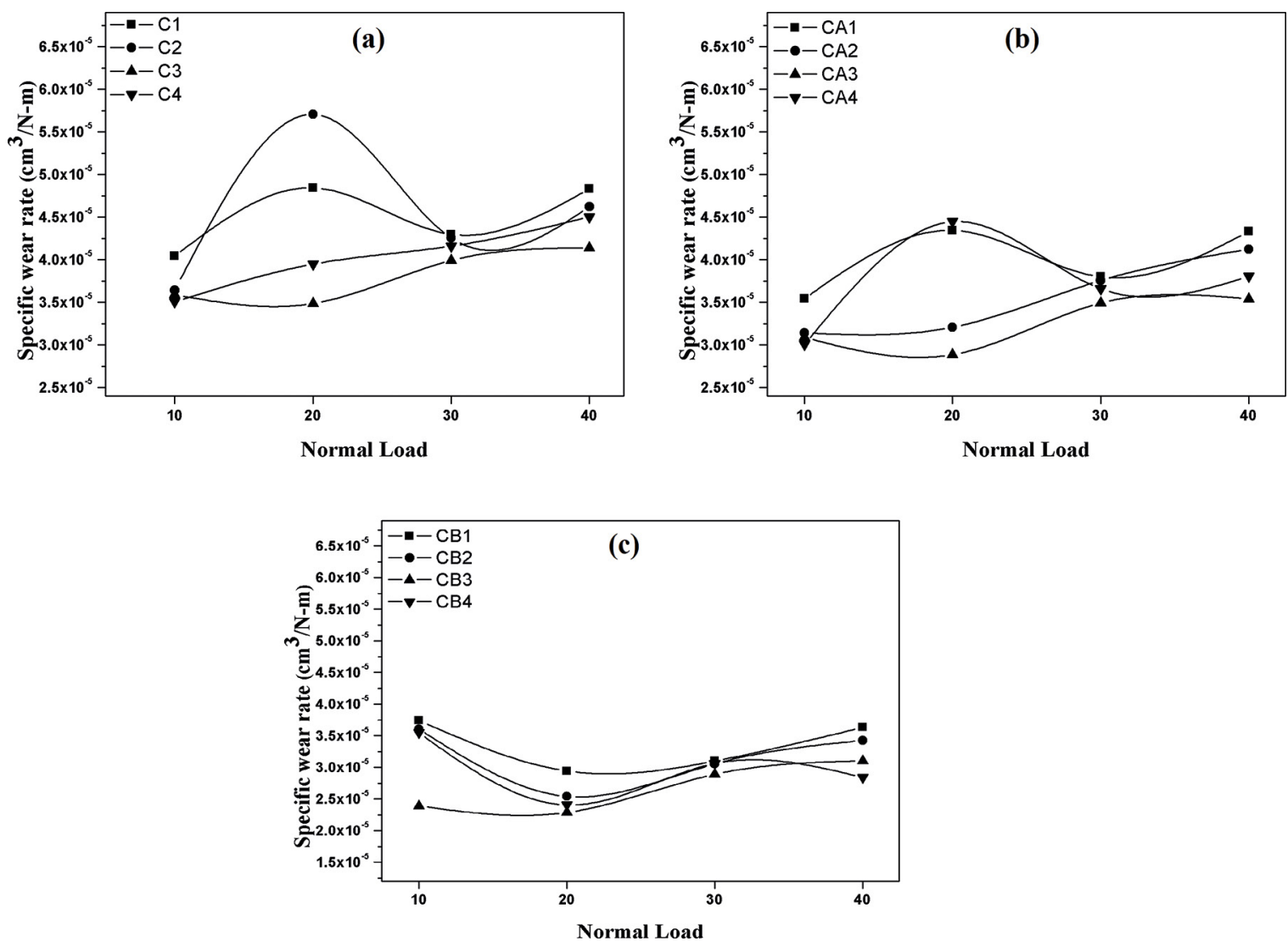

Figure 3. Effect of normal load on the specific wear rate for (a) Untreated (b) Alkali treated (c) Benzoyl chloride treated jute fiber-epoxy composites. (constant sliding distance: $50 \mathrm{~m}$, and abrasive size: $300 \mathrm{~mm}$ ). 

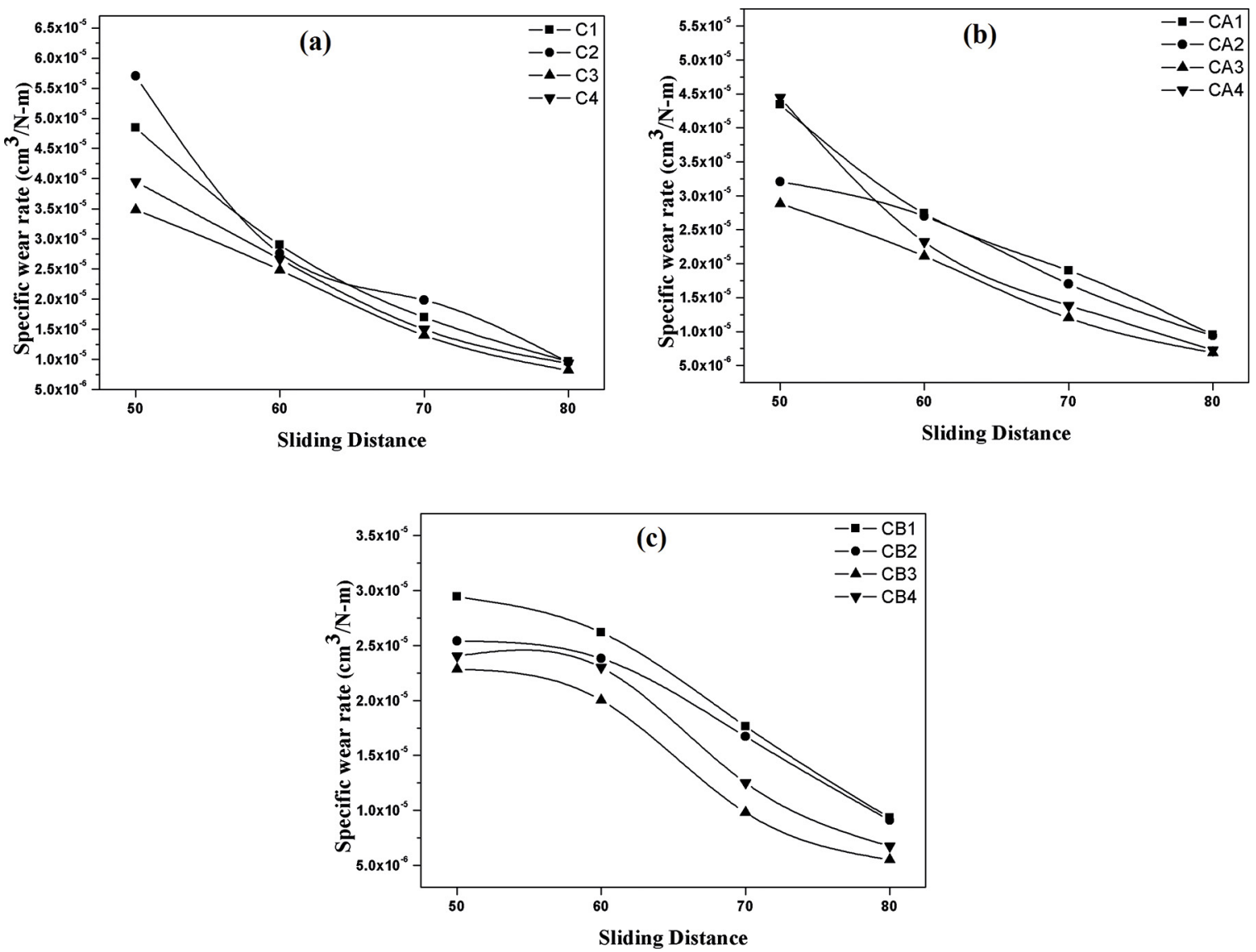

Figure 4. Effect of sliding distance on the specific wear rate of (a) Untreated (b) Alkali treated (c) Benzoyl chloride treated jute fiber-epoxy composites. (constant normal load: $20 \mathrm{~N}$ and abrasive size: $300 \mathrm{~mm}$ ).

more to facilitate failure in the jute fibers (i.e., much higher amount of energy is required to facilitate fiber failure). Hence, the rate at which the material is removed with respect to the sliding distance decreases. Similar type of observations was found by other researchers. ${ }^{46-49}$

A low specific wear rate was found in benzoyl chloride treated based composite with $30 \mathrm{wt} . \%$ fiber loading followed by the alkali treated and untreated composite in both the Figures 3 and 4. It is evident from Figure 3 that benzoyl chloride treated fiber composites i.e., Figure 3 (c) shows the minimum specific wear as compared to untreated (Figure 3 (a)) and alkali treated composite (Figure 3 (b)). Likewise, Figure 4 (c) represents the minimum specific wear rate. This may be due to the reduced number of cellulose hydroxyl groups which are presented for moisture intake, reduced hydrophilicity of fiber surface and minimize swelling of the fiber by producing a cross-linked network due to covalent bonding between matrix, fiber. Similar observation is also reported by the past researchers. ${ }^{39}$

The composites with $30 \mathrm{wt} . \%$ fiber loading show least specific wear rate at a different sliding distance and normal load. This may be happening because of good interfacial bonding between the fiber and matrix which in turn increases the wear resistance of the composites. With the addition of $10 \mathrm{wt} . \%$ and $20 \mathrm{wt} . \%$ fiber loading composites result in poor abrasive wear resistance than composites with $30 \mathrm{wt} . \%$ fiber loading. The specific wear rate of composites with $40 \mathrm{wt} . \%$ fiber loading is more than the composites with $30 \mathrm{wt} . \%$ fiber loading. The increase in specific wear rate at higher fiber loading might have occurred due to improper wetting of fibers which leads to weak interfacial bonding between the fiber and matrix. It is also found by the researchers that the poor interfacial adhesion at higher fiber content results in increased wear rate of lantana camara fiber-reinforced composites. $^{\mathbf{8}}$

\subsection{Surface morphology}

Normally, abrasive wear occurs by three different mechanisms, i.e. micro-ploughing, micro-cutting, and microcracking. ${ }^{44,50}$ To recognize the abrasive wear mechanism, the worn surfaces of composite specimens were studied using SEM. Dry and loose abrasive particles are used in threebody abrasive wear, the material removal rate depends on a number of parameters which controls the extent of work required to provide failure in the material. ${ }^{43}$ In three-body 
abrasion study, the abrasive particles which act as the third body comes in contact with composite material mainly by any of the following three ways: (i) Firstly, freely falling particles gain energy, after coming in contact with the highspeed rubber wheel, and strike the material, resulting in pits formation, or plastic deformation either of the matrix or fiber; (ii) Secondly, particles becomes embedded into the softer rubber wheel and slides over the surface of the material; and (iii) Thirdly, particles roll between the rubber wheel and material, causing plastic deformation to the composite material. ${ }^{51}$

A wear interface or improper compatibility between fiber and matrix may lead to fiber pull out an instead fracture, and may reduce the resulting wear properties. ${ }^{39}$

Figure 5(a) (b) and (c) represents the SEM images of composites with $30 \mathrm{wt} . \%$ of fiber loading subjected to normal of $10 \mathrm{~N}$ with three variations such as untreated, alkali-treated and benzoyl chloride treated respectively. In Figure 5 (a) Shows the low wear resistance as compared to the alkali and benzoyl treated composites, this may happen due to the presence of cellulosic structure which is preventing the property of interfacial adhesion between the fiber and the matrix. For the improper adhesion, more fiber breakage is seen in Figure 5 (a). Fibers were severely damaged and caused discontinuity and de-bonding in this case. Also more cracks presence in case of untreated composites. With the inclusion of chemical treatment such as alkali and benzoyl chloride treatment in Figure 5(b) and (c) which minimizes the fiber cracking and fiber ploughing in abraded surface of composites. It may due to that a protective layer creates because of the layer which would provide a more uniform distribution of interface stresses with the lower magnitude and thus became conductive to lower wear. ${ }^{39}$ Figure 5(c) shows the minimum wear loss as compared to Figure 5(a) and (b).

With increasing in normal load $(40 \mathrm{~N})$, more surface damage is produced by fracture of the fiber or damage of the matrix which results in debonding of the fibers as shown in Figure 6(a) (b) and (c). Figure 4 (a) indicates the untreated fiber whereas Figure 6(b) and shows the alkali treated and benzoyl chloride treatment with having $40 \mathrm{~N}$ loads. The fracture of the fiber bundle and incomplete distribution of the fiber and matrix by forming the cavities between them shown in Figure 6(a). Compare to the all three images, images 6(c) is depicting good wear resistance because of increases the adhesion between the fiber and the matrix which intern reduces the cavities formation. Smooth grooves are seen with few surface cracks and fiber pull-out concentrated in different areas.
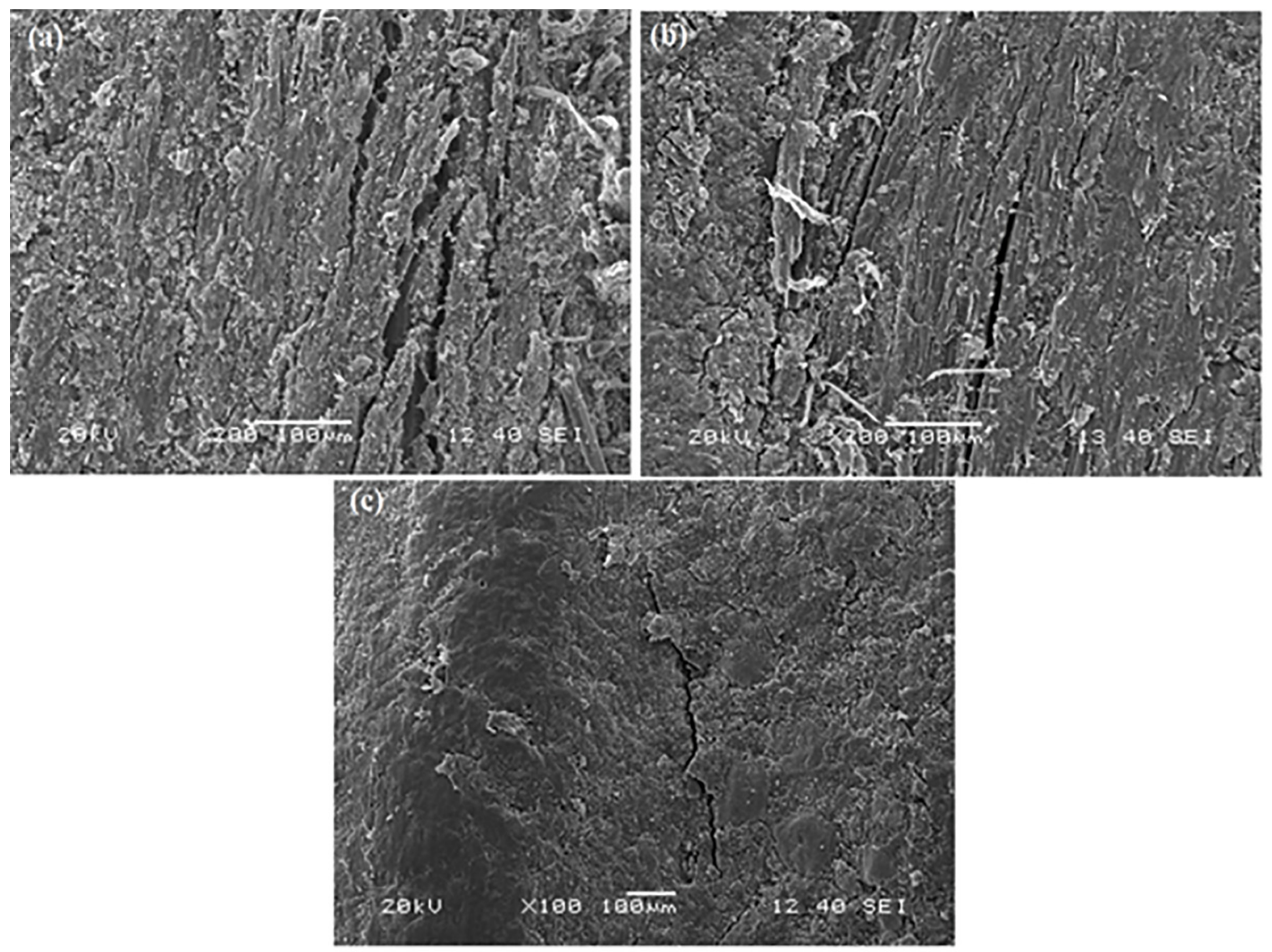

Figure 5. SEM images of (a) Untreated (b) Alkali treated and (c) Benzoyl chloride treated composite surfaces after three body abrasion at $30 \mathrm{wt} \%$ of fiber loading subjected to Normal load of $10 \mathrm{~N}$. 

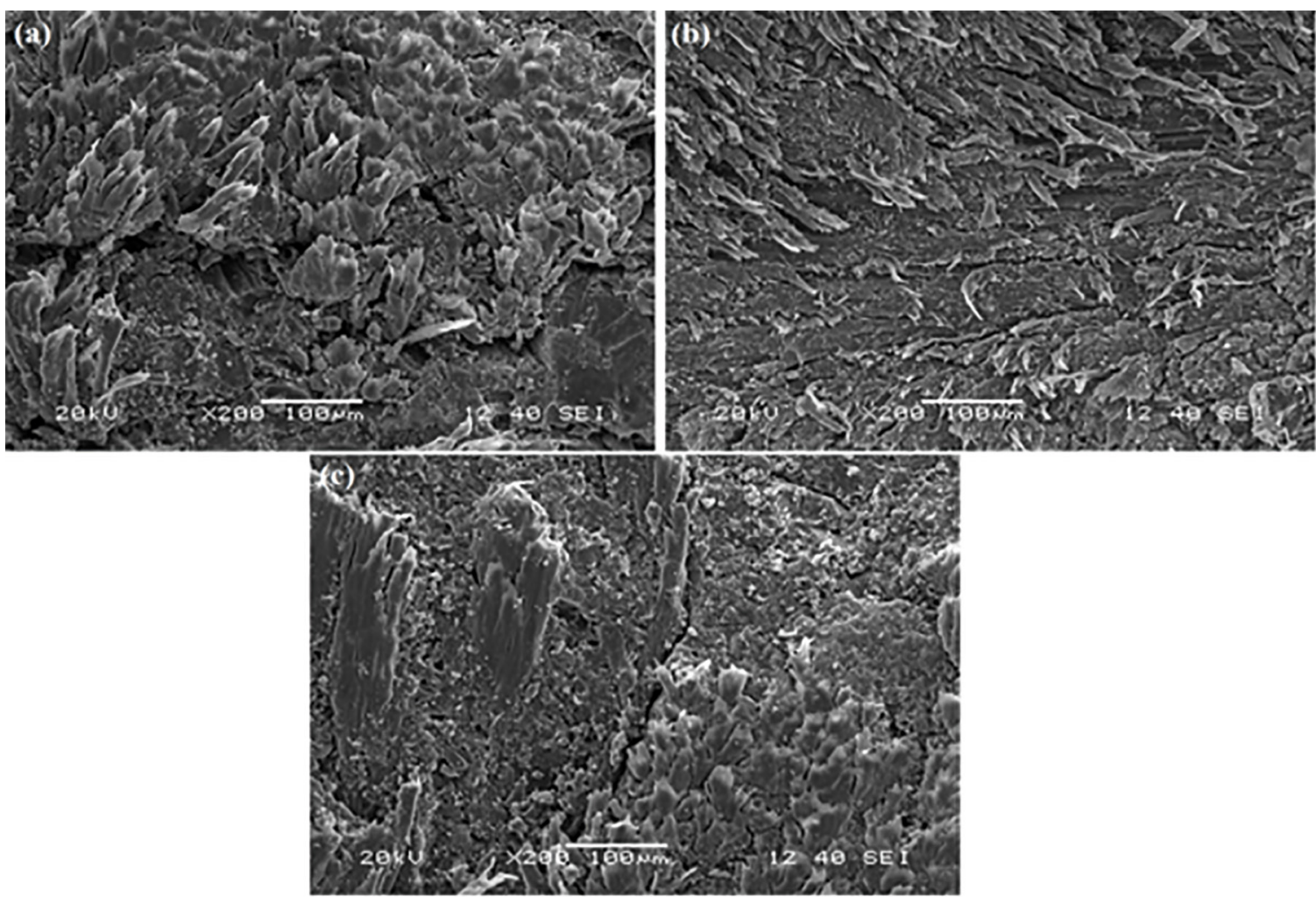

Figure 6. SEM images of (a) Untreated (b) Alkali treated and (c) Benzoyl chloride treated composite surfaces after three body abrasion at $30 \mathrm{wt} . \%$ of fiber loading subjected to Normal load of $40 \mathrm{~N}$.

Figure 5 and 6 represents the composites with low load $(10 \mathrm{~N})$ and high load $(40 \mathrm{~N})$ with $30 \mathrm{wt} . \%$ of fiber loading. Comparisons to all the cases high load composites are rougher than the low load composites and maximum wear rates are found in the case of high load composites. Benzoylation treatment of low load composites exhibits less matrix distortion and wear debris as seen in Figure 5(c), also wear tracks are visible on the surface of all samples.

Figure 7 (a) (b) and (c) shows the consequences of abrasion on composites reinforced with $30 \mathrm{wt} \%$ of jute fiber with three different variations (Figure 7(a): untreated composite, Figure 7 (b): alkali treated composite, Figure 7(c): benzoyl chloride composite) when tested at sliding distance of $50 \mathrm{~m}$. Figure 7 (a) depicts the formation of fiber pull-out and grooves over the abraded surface of the composite. Whereas in the case of alkali treatment, only fiber pull out happens and in the case of benzoylation, it minimizes the groove and outer surface appeared smoother. Wear debris is also detected in all the figures(Figure $7(\mathrm{a}-\mathrm{c})$ ). Minimum wear found out in Figure 7(c) as compared to untreated and alkali treated composite because of well bonding between fiber and matrix.

Figure 8 (a-c) depicts the three body abrasion on composites reinforced with 30 wt.\% of jute fiber with three different variations (Figure 8(a): untreated composite, Figure 8(b): alkali treated composite, Figure 8(c): benzoyl chloride composite) when tested at sliding distance of 80 $\mathrm{m}$. In figure 8(a) represents the untreated composites with Smooth grooves with few surface cracks in different regions. Micro-ploughing is considered by the formation of deep grooves in wear mechanism and material removal found. In the case of alkali treatment in Figure 8(b), minimization of grooves are found. With the comparison of Figure (a) (b) and (C), Figure 8(c) is depicting good wear resistance and have minimum specific wear rate. In this figure damage of fiber was not found; therefore, it can be called as matrix damage dominating.

Figure 7 and 8 indicates the composites with low sliding distance $(50 \mathrm{~m})$ and sliding distance $(80 \mathrm{~m})$ with $30 \mathrm{wt} . \%$ of fiber loading. With the comparison of all the cases, it is clearly visible that larger depth grooves and more damage of the sample are observed at low sliding distance abrasion. It is may be due to the fact that although the surface area of contact is same for both the sliding distances whereas the duration of contact is more in the case of low sliding distance. ${ }^{35}$ Minimum wear rate found in benzoyl treated composites with maximum sliding distance in Figure 8(c). Scratch and pits are also observed over the surface of the sample which was subjected to higher sliding distance also higher debris formation found. The smooth, intact and well-bonded layers were also formed and wear debris are minimized. 

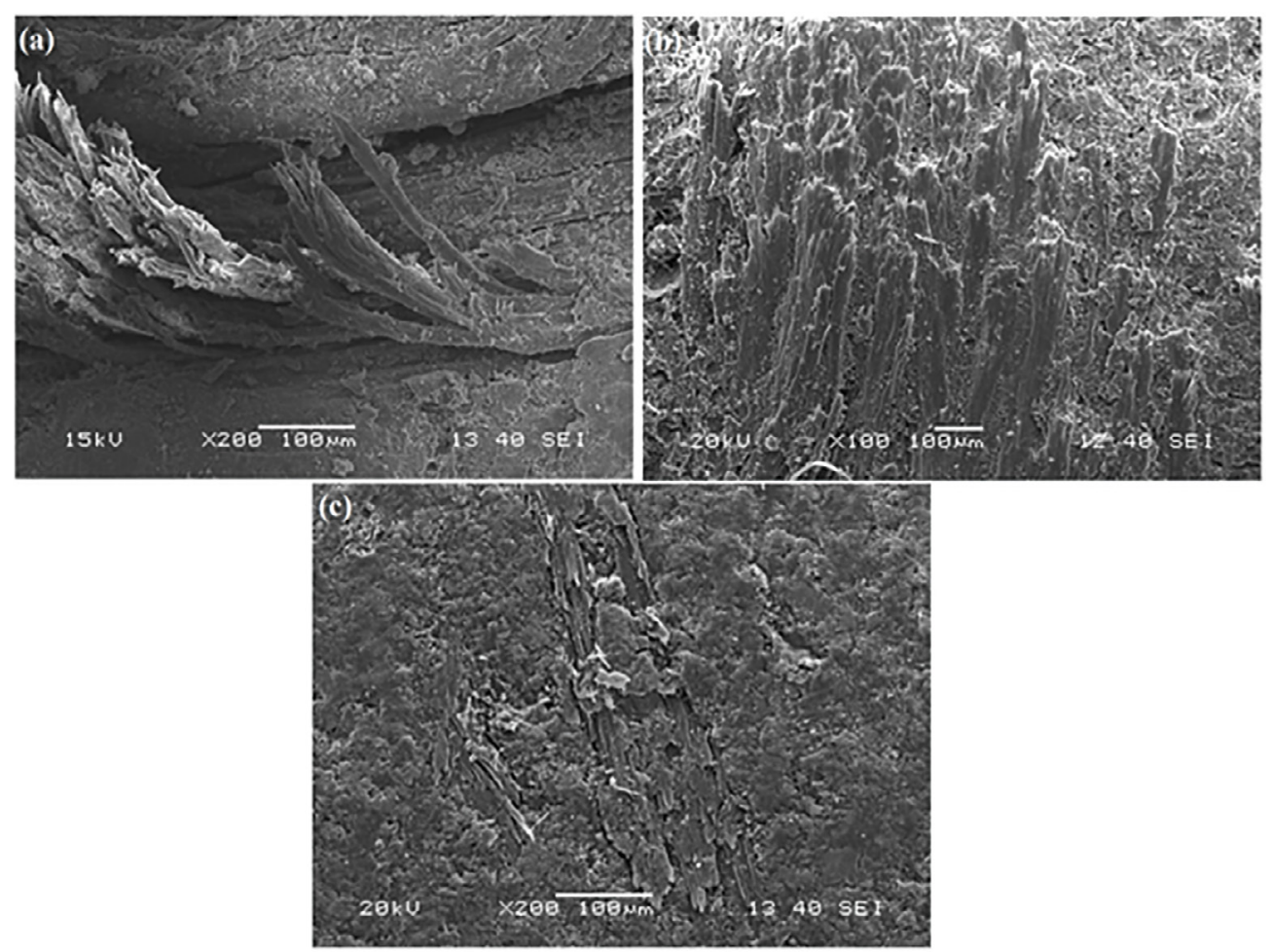

Figure 7. SEM images of (a) Untreated (b) Alkali treated and (c) Benzoyl chloride treated composite surfaces after three body abrasion at $30 \mathrm{wt} . \%$ of fiber loading subjected to Sliding distance of $50 \mathrm{~m}$.
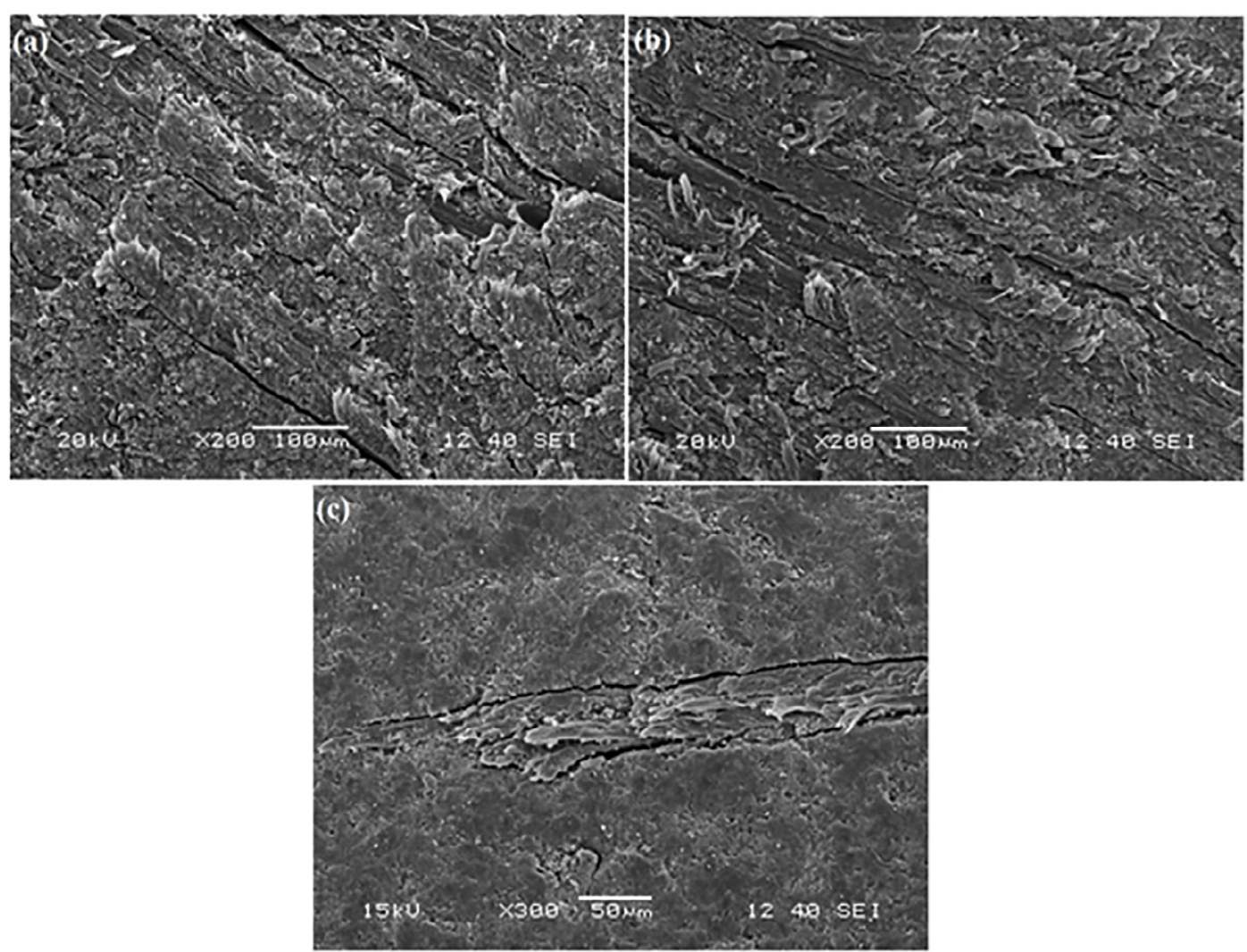

Figure 8. SEM images of (a) Untreated (b) Alkali treated and (c) Benzoyl chloride treated composite surfaces after three body abrasion at $30 \mathrm{wt} . \%$ of fiber loading subjected to Sliding distance of $80 \mathrm{~m}$. 


\section{Conclusions}

Based on the three-body abrasive wear study of the pretreated jute fiber-reinforced epoxy composites, the following conclusions can be drawn:

- $\quad$ Successful fabrication of epoxy based polymer composites reinforced with untreated and chemically treated (alkali treatment and benzoyl chloride treatment) jute fiber mats by simple hand lay-up technique has been achieved.

- The design of experiments based on Taguchi analysis has been carried out for the parametric optimization in order to achieve the minimum specific wear rate of the un-treated and treated based bidirectional jute epoxy composites. The parametric combination, i.e. sliding distance of $70 \mathrm{~m}$, fiber loading of $30 \mathrm{wt} . \%$, a normal load of $10 \mathrm{~N}$, and abrasive size of $200 \mathrm{~mm}$ forms an optimum condition for minimum specific wear rate found at benzoyl treated composite.

- $\quad$ ANOVA performed on the experimental results helped in identifying the critical factors which influence the abrasive wear. According to ANOVA results, the normal load $(\mathrm{p}=0.001)$, fiber loading $(\mathrm{p}=0.010)$ and abrasive Size $(\mathrm{p}$ $=0.037$ ) have great influence on specific wear rate. However, sliding distance $(p=0.229)$ is the least significant effect on the specific wear rate of the composites.

- $\quad$ Specific wear rate of the composites prominently influenced by the normal load and sliding distance. Study reveals that the specific wear rate of the jute epoxy composites decreases with increase in sliding distance whereas specific wear rate of the composites increases with the increase in normal load. The specimens with 30 wt.\% fiber loading exhibits minimum specific wear rate at different sliding distances and normal loading conditions in steady state condition.

- On comparison, Benzoyl chloride treated based composite notably gave better abrasive wear resistance than the untreated and alkali treated based composite. This was due to the high-interfacial adhesion and low-composite porosity.

- $\quad$ The SEM studies of worn surfaces have revealed various wear mechanisms such as micro-ploughing, formation of debris, micro cracking and fiber matrix de-bonding.

\section{References}

1. Hutchings IM. Tribology: Friction and wear of engineering materials. Oxford: Butterworth-Heinemann; 1992. 280 p.

2. Mishra V, Biswas S. Three-body abrasive wear behaviour of short jute fiber reinforced epoxy composites. Polymer Composites. 2016;37(1):270-278. DOI: 10.1002/pc.23178.
3. Friedrich K, Lu Z, Hager AM. Recent advances in polymer composites' tribology. Wear. 1995;190(2):139-144. DOI: 10.1016/0043-1648(96)80012-3.

4. Lancaster JK. The effect of carbon fibre reinforcement on the friction and wear of polymers. Journal of Physics D: Applied Physics. 1968;1(5):549-560.

5. Lu Z, Friedrich K, Pannhorst W, Heinz J. Wear and friction of a unidirectional carbon fiber-glass matrix composite against various counterparts. Wear. 1993;162-164(Pt B):1103-1113. DOI: 10.1016/0043-1648(93)90129-A.

6. Vishwanath B, Verrna AP, Kameswara Rao CVS. Effect of reinforcement on friction and wear of fabric reinforced polymer composites. Wear. 1993;167(2):93-99. DOI: 10.1016/00431648(93)90313-B

7. Mishra V, Biswas S. Evaluation of three body abrasive wear behaviour of bidirectional jute fiber reinforced epoxy composites. Journal of Industrial Textiles. 2015;44(5):781-797. DOI: $10.1177 / 1528083713516663$

8. Deo C, Acharya SK. Effects of fiber content on abrasive wear of Lantana Camara fiber reinforced polymer matrix composite. Indian Journal of Engineering \& Materials Sciences. 2010;17:219-223.

9. Mueller DH, Krobjilowski A. New Discovery in the Properties of Composites Reinforced with Natural Fibers. Journal of Industrial Textiles. 2003;33(2):111-130. DOI: 10.1177/152808303039248.

10. Kannan TG, Wu CM, Cheng KB, Wang CY. Effect of reinforcement on the mechanical and thermal properties of flax/polypropylene interwoven fabric composites. Journal of Industrial Textiles. 2013;42(4):417-433. DOI: 10.1177/1528083712442695.

11. Yilmaz ND, Powell NB, Banks-Lee P, Michielsen S. Multi-fiber needle-punched nonwoven composites: Effects of heat treatment on sound absorption performance. Journal of Industrial Textiles. 2013;43(2):231-246. DOI: 10.1177/1528083712452899.

12. Reis PNB, Ferreira JAM, Antunes FV, Costa JDM. Flexural behaviour of hybrid laminated composites. Composites Part A: Applied Science and Manufacturing. 2007;38(6):1612-1620. DOI: 10.1016/j.compositesa.2006.11.010.

13. Doan TTL, Gao SL, Mäder E. Jute/polypropylene composites I. Effect of matrix modification. Composites Science and Technology. 2006;66(7-8):952-963. DOI: 10.1016/j. compscitech.2005.08.009.

14. Gill NS, Yousif BF. Wear and frictional performance of betelnut fibre-reinforced polyester composite. Proceedings of the Institution of Mechanical Engineers, Part J: Journal of Engineering Tribology. 2009;223(2):183-194. DOI: 10.1243/13506501JET516.

15. Suresha B, Chandramohan G. Three-body abrasive wear behaviour of particulate-filled glass-vinyl ester composites. Journal of Materials Processing Technology. 2008;200(13):306-311. DOI: 10.1016/j.jmatprotec.2007.09.035.

16. Harsha AP, Tewari US, Venkatraman B. Three-body abrasive wear behaviour of polyaryletherketone composites. Wear. 2003;254(7-8):680-692. DOI: 10.1016/S0043-1648(03)00142-X.

17. Yousif BF, El-Tayeb NSM. Wear characteristics of thermoset composite under high stress three-body abrasive. Tribology International. 2010;43(12):2365-2371. DOI: 10.1016/j. triboint.2010.08.010. 
18. Gates JD. Two-body and three-body abrasion: A critical discussion. Wear. 1998;214(1):139-146. DOI: 10.1016/S00431648(97)00188-9.

19. Suresha B, Chandramohan G, Siddaramaiah P, Samapthkumaran P, Seetharamu S. Three-body abrasive wear behaviour of carbon and glass fiber reinforced epoxy composites. Materials Science and Engineering: A. 2007;443(1-2):285-291. DOI: 10.1016/j.msea.2006.09.016.

20. Suresha B, Chandramohan G, Kishore, Sampathkumaran P, Seetharamu S. Mechanical and three-body abrasive wear behaviour of $\mathrm{SiC}$ filled glass-epoxy composites. Polymer Composites. 2008;29(9):1020-1025. DOI: 10.1002/pc.20576.

21. Pati PR, Satapathy A. Processing, characterization and erosion wear response of Linz-Donawitz (LD) slag filled polypropylene composites. Journal of Thermoplastic Composite Materials. 2016;29(9):1282-1296. DOI: 10.1177/0892705714563122.

22. Pati PR, Satapathy A. A Study on Processing, Characterization and Erosion Wear Response of Linz-Donawitz Slag Filled Epoxy Composites. Advances in Polymer Technology. 2015;34(4):21509. DOI: $10.1002 / \mathrm{adv} .21509$.

23. Pati PR, Satapathy A. Prediction and simulation of wear response of Linz-Donawitz (LD) slag filled glass-epoxy composites using neural computation. Polymers for Advanced Technologies. 2015;26(2):121-127. DOI: 10.1002/pat.3421.

24. Suresha B, Ramesh BN, Subbaya KM, Chandramohan G. Mechanical and Three-Body Abrasive Wear Behaviour of Carbon-Epoxy Composite With and Without Graphite Filler. Journal of Composite Materials. 2010;44(21):2509-2519. DOI: 10.1177/0021998310369589.

25. Gustafsson E. Investigation of Friction Between Plastic Parts. [Master's Thesis]. Göteborg: Chalmers University of Technology; 2013.

26. Kukureka SN, Hooke CJ, Rao M, Liao P, Chen YK. The effect of fibre reinforcement on the friction and wear of polyamide 66 under dry rolling-sliding contact. Tribology International. 1999;32(2):107-116. DOI: 10.1016/S0301-679X(99)00017-1.

27. Stanković M, Vencl A, Marinković A. A Review of the Tribological Properties of PTFE Composites Filled with Glass, Graphite, Carbon or Bronze Reinforcement. In: Proceedings of the $13^{\text {th }}$ International Conference on Tribology - SERBIATRIB '13; 2013 May 15-17; Kragujevac, Serbia. p. 15-17.

28. Basavaraj E. Investigation on Mechanical, Tribological and Morphological Behaviours of Polymer Composites. [Ph.D. Thesis]. Mysore: University of Mysore; 2013.

29. Sole BM, Ball A. On the abrasive wear behaviour of mineral filled polypropylene. Tribology International. 1996;29(6):457-465. DOI: 10.1016/0301-679X(95)00098-O.

30. Evans DC, Lancaster JK. The Wear of Polymers. In: Scott $\mathrm{D}$, ed. Treatise on Materials Science and Technology. Volume 13. New York: Academic Press; 1979. p. 85-139.

31. Cenna AA, Doyle J, Page NW, Beehag A, Dastoor P. Wear mechanisms in polymer matrix composites abraded by bulk solids. Wear. 2000;240(1-2):207-214. DOI: 10.1016/ S0043-1648(00)00365-3.
32. Chand N, Naik AM, Khira HK. Development of UHMWPE modified PP/PET blends and their mechanical and abrasive wear behaviour. Polymer Composites. 2007;28(2):267-272. DOI: $10.1002 / \mathrm{pc} .20302$.

33. Cirino M, Pipes RB, Friedrich K. The abrasive wear behaviour of continuous fibre polymer composites. Journal of Materials Science. 1987;22(7):2481-2492. DOI: 10.1007/ BF01082134.

34. Hashmi SAR, Neogi S, Pandey A, Chand N. Sliding wear of PP/UHMWPE blends: effect of blend composition. Wear. 2001;247(1):9-14. DOI: 10.1016/S0043-1648(00)00513-5.

35. Mishra V, Biswas S. Three-Body Abrasive Wear Behaviour of Needle-Punch Nonwoven Jute Fiber Reinforced Epoxy Composites. International Polymer Processing. 2014;29(3):356-363. DOI: 10.3139/217.2788.

36. Goriparthi BK, Suman KNS, Rao NM. Effect of fiber surface treatments on mechanical and abrasive wear performance of polylactide/jute composites. Composites Part A: Applied Science and Manufacturing. 2012;43(10):1800-1808. DOI: 10.1016/j.compositesa.2012.05.007.

37. Chand N, Dwivedi UK. Effect of coupling agent on abrasive wear behaviour of chopped jute fibre-reinforced polypropylene composites. Wear. 2006;261(10):1057-1063. DOI: $10.1016 /$ j.wear.2006.01.039.

38. Yousif BF, El-Tayeb NSM. High-stress three-body abrasive wear of treated and untreated oil palm fibrereinforced polyester composites. Proceedings of the Institution of Mechanical Engineers, Part J: Journal of Engineering Tribology. 2008;222(5):637-646. DOI: $10.1243 / 13506501$ JET412.

39. Divya GS, Kakhandaki A, Suresha B. Wear Behaviour of Coir Reinforced Treated and Untreated Hybrid Composites. International Journal of Innovative Research and Development. 2014;3(5):632-639.

40. Kalia S, Dufresne A, Cherian BM, Kaith BS, Avérous L, Njuguna J, et al. Cellulose-Based Bio-and Nanocomposites: A Review. International Journal of Polymer Science. 2011;2011:837875. DOI: 10.1155/2011/837875.

41. ASTM International. ASTM G65-04 Standard Test Method for Measuring Abrasion Using the Dry Sand/Rubber Wheel Apparatus. West Conshohocken: ASTM International; 2004. DOI: $10.1520 / \mathrm{G} 0065-04$.

42. Ross PJ. Taguchi Techniques for Quality Engineering: Loss Function, Orthogonal Experiments, Parameter and Tolerance Design. New York: McGraw-Hill, 1988; p. 10-50.

43. Chand N, Naik A, Neogi S. Three-body abrasive wear of short glass fibre polyester composite. Wear. 2000;242(1-2):38-46. DOI: 10.1016/S0043-1648(00)00398-7.

44. Siddhartha, Gupta K. Mechanical and abrasive wear characterization of bidirectional and chopped E-glass fiber reinforced composite materials. Materials \& Design. 2012;35:467-479. DOI: 10.1016/j. matdes.2011.09.010. 
45. Chand N, Dwivedi UK. Influence of fiber orientation on high stress wear behaviour of sisal fiber-reinforced epoxy composites. Polymer Composites. 2007;28(4):437-441. DOI: 10.1002/ pc.20286.

46. Basavarajappa S, Joshi AG, Arun KV, Kumar AP, Kumar MP. Three-Body Abrasive Wear Behaviour of Polymer Matrix Composites Filled with SiC Particles. PolymerPlastics Technology and Engineering. 2009;49(1):8-12. DOI: 10.1080/03602550903206407.

47. Chairman CA, Babu SPK. Three-body abrasive wear behaviour of basalt and glass fabric reinforced epoxy composites. Applied Mechanics and Materials. 2012;121-126:534-538. DOI: 10.4028/ www.scientific.net/ AMM.121-126.534.
48. Manoharan S, Suresha B, Bharath PB, Ramadoss G. Investigations on three-body abrasive wear behaviour of composite brake pad material. Plastic and Polymer Technology. 2014;3:10-18.

49. Suresha B, Chandramohan G, Jawali ND. Effect of Short Glass Fiber Content on Three-Body Abrasive Wear Behaviour of Polyurethane Composites. Journal of Composite Materials. 2007;41(22):2701-2713. DOI: 10.1177/0021998307078730.

50. Stachowiak GW, Batchelor AW. Abrasive, erosive and cavitation wear. In: Stachowiak GW, Batchelor AW. Engineering Tribology. Boston: Butterworths-Heinemann, 2001: p. 481-531.

51. Chand N, Neogi S. Mechanism of material removal during three-body abrasion of FRP composite. Tribology Letters. 1998;4:81-85. DOI: 10.1023/A:1019138718283. 